Revista Iberoamericana, Vol. LXXIX, Núm. 242, Enero-Marzo 2013, 149-162

\title{
LITERATURAS SIN RESIDENCIA FIJA: POÉTICAS DEL MOVIMIENTO EN LA NOVELÍSTICA CENTROAMERICANA CONTEMPORÁNEA
}

\author{
POR \\ AleXANDRA ORTiz WaLLNER \\ Freie Universität Berlin
}

SENSIBILIDADES DEL DESPLAZAMIENTO Y TRAYECTOS FISURADOS

Los escenarios centroamericanos de finales del siglo xx e inicios del siglo xxi son escenarios fisurados, escenarios que bajo los efectos de la actual fase de globalización acelerada despliegan disonancias y proliferaciones de fisuras en las narraciones del presente y las experiencias del sujeto con respecto a las expectativas que la modernidad ha suscitado. Las "fisuras narrativas" (Geyer y Bright 1052-53) se manifiestan en procesos contradictorios y conflictivos provocados por la movilización de personas y circulación de bienes materiales y simbólicos que escapan a los esfuerzos por sujetarlos a un orden (ver Leyva, "Las fisuras").

El momento de ruptura epistemológica que marcó a las producciones literarias y culturales centroamericanas a partir de la década de 1970 ha sido discutido a lo largo de las décadas pasadas a través de imágenes que intentan dar cuenta de la condición asimétrica que singularizaba en ese entonces a este puente entre las dos Américas. Expresiones como "cultura dispersa, mutilada y bajo acecho" (Ramírez 361), "cultura del miedo” (Cuevas Molina 19-89), “literatura de la violencia”(Liano 259-71) o “utopías deshabitadas" (Mackenbach, Unbewohnte Utopie 522-27), por ejemplo, comparten la idea de una profunda escisión en estos escenarios. Creo que estas interpretaciones deben ser incluidas y comprendidas como elementos de una histoire croisée (Werner y Zimmermann), esto es, como parte de una historia (literaria) transcultural y transnacional de las relaciones y tensiones que han surgido entre la producción ficcional, la cultural y la social: se trata de una historia que aspira a superar la limitación de la perspectiva unívoca de lo nacional y de las literaturas nacionales. Una historia que, en palabras de Ana Patricia Rodríguez, articula la posibilidad de aprehender dichas producciones desde sus contradicciones, desde el borramiento de los límites entre ficción y dicción, entre guerra y paz, entre nación e istmo, puesto que es allí donde la fraccionalización y la 
friccionalización se vuelven operaciones que dan cuenta de los cruces, transgresiones y reconfiguraciones de las comunidades culturales centroamericanas (223-35).

En este sentido, la condición asimétrica y fragmentada de los espacios sociales, políticos y culturales centroamericanos se despliega transversalmente por sus territorios, regiones y zonas, sean reales o imaginarios. Gracias a estos actos de movilidad, los trayectos que siguen los modos de producción, circulación y consumo de bienes culturales en estos espacios son visibilizados mostrando su no-reducción a los límites y fronteras nacionales, sino más bien sus desplazamientos por cartografías, geografías y geopolíticas mucho más amplias. En el presente trabajo me interesa profundizar en este descentramiento de la perspectiva de lo nacional, hasta hace pocos años dominante y normativa de los discursos sobre las producciones literarias y culturales centroamericanas, girando el interés hacia una perspectiva de las dinámicas de la circulación y de los movimientos que recorren los espacios y territorios de lo centroamericano en tres novelas publicadas a partir de 1989. Considero estos textos como novelas sobre el movimiento y dado que cada una de ellas contiene y muestra una amplia gama de formas del movimiento y, del desplazamiento, concentraré mi lectura especialmente en aquellos tipos de movimientos vinculados a la comprensión del espacio y la subjetividad, con el fin de indagar en las implicaciones hermenéuticas y poéticas que de estos procesos se pueden desprender.

Así, una perspectiva que se incline por los recorridos y los tránsitos en el espacio permite una comprensión más amplia y compleja de los vínculos y las dimensiones transnacionales, transregionales y transareales de las producciones literarias y culturales. La literatura, y de forma ejemplar la novela -entendida en el sentido bajtiniano como producción socio-histórica y cultural que se distingue por ser un repositorio dinámico e interactivo de voces y narrativas de significación cultural-, se va a manifestar en este periodo de fisuras narrativas como una de las dimensiones principales que inauguran un proceso de negociación (inter)cultural sobre las formas de vida y de sobrevivencia en Centroamérica. Así, la novela, caracterizada por ser un género particularmente móvil -que integra y transgrede fronteras genéricas, que oscila entre la ficción y la dicción-, ocupa en los procesos de transición política y sociocultural del siglo xx al xxI un lugar sobresaliente en la articulación crítica de espacios discursivos y modelaciones de formas de vida y subjetividad.

El contenido que simbólicamente se le ha atribuido a la década de los noventa como el momento político coyuntural que marca el ocaso y fracaso de las formas de gobierno autoritarias y dictatoriales dominantes, así como de las luchas armadas revolucionarias de izquierda que transformaron y modelaron en distintos grados a los países centroamericanos entre las décadas de los sesentas y los noventas, terminó afianzando otras formas asimétricas de negociación de la sociabilidad y la convivencia. Sin embargo, este periodo de transición, posrevolucionario y de posguerra, resultará relevante para los esfuerzos por recomponer el tejido social y promover la configuración

\footnotetext{
Revista Iberoamericana, Vol. LXXIX, Núm. 242, Enero-Marzo 2013, $149-162$
ISSN 2154-4794 (Electrónico)
} 
de nuevos espacios sociales y culturales (ver por ejemplo los trabajos de Cazali y López). Es especialmente a partir de los noventa que empiezan a publicarse estudios preocupados por abordar ciertos aspectos de las culturas de Centroamérica, con especial énfasis en la literatura, producidos tanto en las academias del área centroamericana como en las academias estadounidense y europeas. En todos, la literatura ocupa un lugar central y privilegiado como parte de los procesos y dinámicas culturales del área (Ortiz Wallner y Mackenbach). Sin embargo, a pesar de otorgársele dicho lugar, la literatura es definida a partir de nociones que la demarcarán claramente: "arma ideológica de descolonización” o “instrumento de cuestionamiento dela realidad social” (véase Beverley y Zimmermann; Leyva, "Narrativa”); son aún pocas las investigaciones que empiezan a focalizar los movimientos y desplazamientos de y en las literaturas centroamericanas (véase Mackenbach, Unbewohnte Utopie; Rodríguez).

La transgresión de fronteras, en un sentido político-territorial y también simbólicodiscursivo, no es un fenómeno nuevo en las producciones literarias centroamericanas. Considero que estas producciones se han caracterizado ya desde el Modernismo hispanoamericano por estar atravesadas por múltiples lógicas del movimiento y del desplazamiento, que incluyen, por un lado, los desplazamientos físicos y los recorridos geográficos de los agentes culturales (intelectuales, cronistas, escritores y viajeros), y, por otro lado, las lógicas del movimiento que van a incidir en la configuración y creación de los mundos ficcionales. En este sentido me interesa plantear la configuración de una "sensibilidad del desplazamiento" - en la misma línea que Ana Pizarro le ha otorgado a las literaturas del Caribe (26)-, que articula las formaciones literarias y culturales más allá de la fronteras nacionales, las cuales han estado marcadas - paradigmáticamente para Centroamérica a lo largo del siglo xx- por momentos de desplazamientos masivos de la población que oscilan entre el destierro, el exilio, la migración y la diáspora, y no menos aún por los movimientos de sus literaturas. Así, esta sensibilidad del desplazamiento registra las posibilidades de comprensión de los procesos históricos y culturales que de ella se desprenden, convirtiéndola en una condición necesaria para la aprehensión y el discernimiento de las formas de vida y convivencia que la producción literaria pone en escena. En los escenarios centroamericanos fisurados emergen las literaturas centroamericanas como "literaturas sin residencia fija” (Ette 23-67).

VoCES EN EL EXILIO: LA DIÁSPORA

La diáspora, primera novela de Horacio Castellanos Moya, narra las experiencias de un grupo de jóvenes revolucionarios salvadoreños en el exilio mexicano, su paulatino y ambiguo desencanto con la militancia y los ideales utópicos revolucionarios, y su posterior rompimiento con “la revolución”. En La diáspora, este múltiple distanciamiento se formula en la diégesis a través de la problematización de los temas de la traición de

\footnotetext{
Revista Iberoamericana, Vol. LXXIX, Núm. 242,
ISSN 0034-9631 (Impreso)
} 
los ideales y de las solidaridades al interior de la guerrilla, la subordinación del arte a la política y las experiencias del exilio. En este plano me interesa destacar como eje de las estrategias narrativas la introducción de múltiples perspectivas que dan cuenta del fracaso de "la revolución”, ofreciendo al lector un coro de voces para su comprensión (la cual sólo puede ser parcial). Por medio de esta estrategia, la novela pone en escena el dilema que viven los personajes desde su condición de extranjeros en el país del Norte. Estar en el exilio es, para varios de los personajes, una forma de estar a la deriva, de ser náufragos en la incertidumbre. El movimiento que impone el exilio no solamente afecta la condición física de estos personajes como individuos desplazados, sino también a una sensibilidad que se ve expuesta a una negociación continua según términos y coordenadas variables.

En el centro de los acontecimientos que llevan al encuentro de los personajes desplazados hacia la Ciudad de México está el asesinato de dos líderes comandantes guerrilleros en el seno del movimiento revolucionario centroamericano. La novela opera aquí una apropiación de la realidad extraliteraria al incluir los llamados "Sucesos de abril" en la trama narrativa. Estos "sucesos" son un tema que sólo ha sido tangencialmente discutido en la esfera pública centroamericana en años recientes. Dos ejemplos junto a la novela de Castellanos Moya son un breve artículo periodístico del escritor salvadoreño Rafael Menjívar Ochoa publicado en el semanario virtual Centroamérica 21 en mayo de 2007 y la novela de la costarricense Anacristina Rossi, Limon reggae, publicada en San José en junio de 2007. En La diáspora, uno de sus protagonistas, Juan Carlos, reflexiona tras recibir la noticia de las muertes:

Por eso, cuando comprendió que Marcial y Ana María estaban irreversiblementemuertos, Juan Carlos experimentó una desoladora sensación de orfandad, de desamparo. También fue víctima de un sentimiento de culpa, de pecado (porque los caínes estaban dentro de ellos). Se trataba de una enorme conspiración metafísica, que había movido fuerzas incontrolables, insospechadas, y de pronto los había transformado de inmaculados ángeles revolucionarios en vulgares seres humanos, tan criminales como sus adversarios. (113)

Poco después Juan Carlos confirmará que “algo se había roto dentro de [él]” (114) y que su destino había cambiado definitivamente. Como ya ha consignado Héctor M. Leyva, La diáspora es una narración que incorpora tempranamente (la novela misma registra en su última página que fue escrita entre septiembre de 1986 y enero de 1987) un discurso inédito y crítico en la narrativa centroamericana de esos años: la desmitificación-desde su mismo interior-de un proceso que aspira a la revolución. Ahora bien, interesa ver cómo se incorpora este discurso en la novela: La diáspora construye a través de las voces en el exilio una perspectiva múltiple que fisura la visión utópica que predominó en la narrativa revolucionaria y testimonial centroamericana (Leyva, “Narrativa” 387), y esto lo hace a partir del desplazamiento que lleva a los personajes

\footnotetext{
Revista Iberoamericana, Vol. LXXIX, Núm. 242, Enero-Marzo 2013, $149-162$
ISSN 2154-4794 (Electrónico)
} 
a coincidir en una ciudad, en un país, que no es el de origen. Un desplazamiento que junto al abandono del lugar de origen implica una vida marcada por la clandestinidad. A partir de las posiciones que asumen los personajes de La diáspora se crea el relato del exilio desde la confluencia de múltiples voces sobre lo que significa "la revolución" percibida desde la distancia, una confluencia que irónicamente es el resultado de un movimiento centrífugo: la dispersión del pequeño grupo en el D.F.

Este conjunto de historias personales de "la revolución" conforma un paisaje del exilio al unir las experiencias y las voces de quienes viven como Juan Carlos y Gabriel el desencanto y la disidencia; del compromiso de quienes aún aspiran a formar parte de la lucha armada regresando algún día a la lucha en las montañas, como el joven Quique; del Negro, el jefe de la oficina mexicana de prensa del Partido; del Turco, el músico indisciplinado que reclutó a su hermano menor en la lucha, e incluso de quienes, ajenos al conflicto centroamericano como el periodista argentino Jorge Kraus (también exiliado), buscan aprovecharse de la situación para su propio beneficio con el plan de hacer la noticia de los asesinatos de los comandantes un best-seller. Cada una de las voces expresará en determinados momentos de la novela su propia versión y percepción de "la revolución”, una historia personal de los acontecimientos, siendo el punto de vista de personajes como Juan Carlos, el Turco y Gabriel relevantes para descubrir los silencios y vacíos de la lucha revolucionaria, los cuales son comprendidos de forma paradigmática por Juan Carlos en su sensación de orfandad. El viaje hacia el exilio, así como la precaria cotidianidad en el exilio, despojan a los personajes de todo sentimiento de pertenencia.

En la tercera parte de La diáspora una analepsis, otra de las estrategias narrativas muy presentes a lo largo de toda la novela, narra la muerte de Roque Dalton como parte de un episodio de la juventud de Gabriel, "un escritor frustrado" (133), intelectual y docente universitario establecido desde 1979 en México, que intenta concluir su tesis doctoral que versa sobre el tema del escritor y la revolución. Gabriel es un joven profesor de literatura cuando se entera del ajusticiamiento de Dalton a través de la lectura de un volante:

Esa tarde de mediados de mayo de 1975, cuando llegó a la parada de buses de la plaza Morazán, en la zona céntrica de San Salvador, con la intención de abordar una ruta 7 que lo llevara a la universidad, Gabriel vio regados sobre la acera, al capricho del viento, varios volantes: distinguió el emblema del ERP y recogió uno. Su primera reacción fue de incredulidad: no era posible que hubieran matado a Dalton, el más importante poeta de la historia salvadoreña, bajo la acusación de ser un traidor y un agente de la CIA. (Castellanos Moya134)

La noticia que va a transformar profundamente a Gabriel y, hasta cierto punto a poner en marcha su viaje hacia el exilio, se da mientras éste se desplaza por el centro de

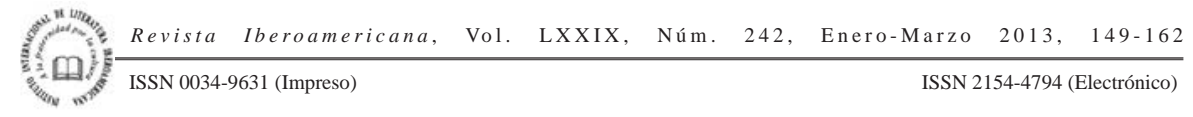


la ciudad. Su acostumbrado recorrido para dirigirse a su lugar de trabajo es interrumpido por la escena de lectura del volante en la parada de buses, un lugar de paso y de tránsito. La parada de autobuses se conforma como un espacio típico de lo que Marc Augé denomina la "sobremodernidad", un tiempo en el cual "las concentraciones urbanas, los traslados de poblaciones y la multiplicación de lo que llamaríamos los 'no lugares'” (40) deslocalizan la cultura en sus relaciones con el tiempo y el espacio:

Los no lugares son tanto las instalaciones necesarias para la circulación acelerada de personas y bienes (vías rápidas, empalmes de rutas, aeropuertos [paradas de buses]) como los medios de transporte mismos o los grandes centros comerciales, o también los campos de tránsito prolongado donde se estacionan los refugiados del planeta. (41)

Gabriel conserva el volante y se monta en el bus para ir a la universidad "masticando la noticia, pensando que no podía ser cierta” (134). La muerte del mito Dalton desencadenará una paulatina transformación en la subjetividad de Gabriel. Más adelante el narrador heterodiegético lanza la pregunta, "Pero, ¿qué significaba Dalton para este profesor de letras?” (134), a lo que responde casi inmediatamente, "Dalton era su paradigma nacional, el hombre que encarnaba [...] la búsqueda de la identidad nacional y el cosmopolitismo" (135). La escena de lectura del volante protagonizada por Gabriel genera una contradicción entre el ciudadano enajenado y el individuo que se conforma como sujeto y se reconoce como parte de algo más general, de una búsqueda común. A través de la interpelación que le hace el volante que anuncia la muerte de Dalton en la parada de buses se va a anunciar la línea de fuga que llevará a Gabriel a un exilio hasta cierto punto voluntario. Del no lugar se desplazará a un fuera de lugar: "Era difícil, además, ser un profesor universitario salvadoreño radicado en México, sin mantener siquiera contacto con un comité de solidaridad” (136). En este otro espacio, su relación con "la revolución”, así como la búsqueda de las posibilidades de convergencia entre arte y política se van a ver corridas hacia otra parte, pues el Partido termina condicionando el sentido de pertenencia al mismo a cambio de ceder a las presiones de incorporarse por completo a la causa. Gabriel opta por retirarse, un gesto que conlleva un movimiento quizás aún más determinante: el que le lleva de una comunidad política que él identifica y con la cual se ha identificado al lugar fuera de la misma, a una condición ex-céntrica y de dislocación, a una ruptura con su identificación con la causa y con su identidad como militante.

Así, a través de las voces que enuncian situaciones de desamparo y quebranto psíquico, ideológico y corporal, La diáspora representa en el movimiento de la dispersión espacial y de las voces la generación de una dislocación de la subjetividad. El conjunto de voces que circula por la novela muestra en el movimiento doble de coincidencia y dispersión de las mismas que, a pesar de estar allí reunidas, a dichas voces ya no les es posible constituir comunidad. De este mismo modo, tanto el sentido de pertenencia,

\footnotetext{
Revista Iberoamericana, Vol. LXXIX, Núm. 242, Enero-Marzo 2013, $149-162$
ISSN 2154-4794 (Electrónico)
} 
tan anhelado por algunos de los personajes, como su enraizamiento (sea en un territorio nacional, en una agrupación política, en un ideal, en una comunidad imaginada) serán cuestionados precisamente por los movimientos que cruzan y componen la novela.

ENTRE (DOS) ORILLAS, ENTRE (DOS) MUNDOS:

LA ORILLA AFRICANA Y EL TREN A TRAVANCORE (CARTAS INDIAS)

A estas dos novelas del guatemalteco Rodrigo Rey Rosa las atraviesan aspectos que las vinculan entre sí conformando un mosaico sobre los (des)encuentros entre América y Oriente. Sobre el eje del motivo del viaje, la experiencia (Erfahrung) y la vivencia (Erlebnis) de los dos personajes masculinos y latinoamericanos, quienes alejados de sus lugares de origen se encuentran ubicados como extranjeros en dos ciudades costeras del amplio Oriente -Tánger en el Norte de África, y Madrás (o Chennai), en el sur de la India-, surge un primer punto de encuentro: para ambos personajes el viajar parece ser el único proyecto admisible y realizable. El desplazamiento es una constante en la vida de estos personajes, el movimiento se convierte en una necesidad para sobrevivir en un mundo que se encuentra igualmente en movimiento.

En La orilla africana la ciudad de Tánger es un escenario que condensa tensiones y conflictos históricos, políticos y culturales; es un espacio dinámico marcado por los movimientos que van a llevar a los personajes por diversos recorridos. Así, las vidas disímiles de un joven pastor marroquí, un viajero colombiano y una estudiante universitaria francesa se cruzarán esporádicamente en la narración a partir de sus trayectos por Tánger. A pesar de la fugacidad de estos encuentros, será precisamente gracias a éstos que cada una de las figuras experimentará procesos que transformarán su identidad y reconfigurarán su subjetividad. En este proceso, toda construcción identitaria en apariencia fija y estable va a verse sometida a rupturas y desconfiguraciones en el transcurso de los episodios de la narración. En este sentido, ya en el título se apunta hacia una condición límite y de borde que se condensa en la tensión de la imagen de la orilla: una oscilación entre proximidad y lejanía.

En El tren a Travancore la cuestión de la identidad es abordada ya en la primera parte, en las primeras líneas de la primera carta “A la novia” que el protagonista, un escritor enviado por encargo de un proyecto editorial a esta ciudad de la India, escribe a propósito de su llegada a la ciudad en avión y una conversación que sostuvo con la azafata de Lufthansa: "La identidad no es un problema indio-me dijo [ella] a propósito de nada-, es un problema europeo” (17). Unas líneas más adelante, el anónimo protagonistaescritor le describe a su novia la ciudad en los siguientes términos: "Chennai es tan alegre y cálida como Escuintla o Puerto Culebra, pero amplificados a una pesadilla maltusiana. [...] Los colores son tan brillantes como los de cualquier ciudad tropical de este milenio” (17). O más adelante a propósito de su visita a Mamalapuram: "El

\footnotetext{
Revista Iberoamericana, Vol. LXXIX, Núm. 242,
ISSN 0034-9631 (Impreso)
} 
estado de Tamil Nadu y Guatemala están en la misma latitud, pero me pareció que aquí hay muchísimas más estrellas” (33). Estas comparaciones que oscilan entre diversos espacios geográficos (la India, América) van a ir demarcando en las cartas de El tren a Travancore una noción espacio-temporal dinámica que fluctúa entre lo local y lo global, lo conocido y lo desconocido. Por ejemplo, en una de las cartas titulada "A un viejo amigo", contenida en la misma primera parte, se lee: "Qué bien que Internet haya llegado por fin a Baja Verapaz. Salamá podría ser un nombre árabe, y los indios no saben, a menos que trafiquen en cardamomo, dónde queda Guatemala” (43).

La novela, cuyo subtítulo es (Cartas indias) se divide en dos partes. Cada una muestra una colección de breves cartas -que no consignan la fecha ni la localidad específica de su escritura- que el protagonista envía desde Chennai a los destinatarios mostrados en el índice: la novia, un viejo amigo, el editor, el ahijado, los padres y xx. La única fecha que aparece está al final de la última carta de la segunda parte, dirigida a xx, desde la sociedad teosófica en Adyar donde el protagonista se ha alojado. Las respuestas y el lugar de destino de las cartas solamente pueden ser inferidas por el lector, pues no forman parte de la novela, operándose aquí también un desplazamiento interesante: el lector lee la novela escrita por un escritor guatemalteco (Rey Rosa) que versa sobre un escritor guatemalteco (anónimo) que se ha trasladado a la India para escribir una novela por encargo. Sin embargo, la novela en la novela no llega a ser escrita nunca, así como el viaje a Travancore es solamente anunciado en esta última carta: "Los astros no me han sido avaros en materia de dinero -no mediante las letras como podrías creer-, pero, ¿̇a qué engañarnos? Te daré detalles y tal vez te haga más confesiones en el tren a Travancore" (137).

En La orilla africana el espacio histórico, cultural y geoestratégico de la ciudad de Tánger es configurado como un espacio de encrucijadas, de caminos que se unen y se bifurcan a través de los encuentros azarosos de los personajes que coinciden en la ciudad. Es una ciudad privilegiada por viajeros y visitantes, lugar de llegada y de partida, lugar de tránsito de artistas y escritores, comerciantes y políticos, de oleadas de migrantes hacia Europa. Las descripciones de los recorridos irán configurando parte de las historias (pos)coloniales de las relaciones de Tánger con Europa y con Oriente. Así, en uno de los recorridos de uno de los personajes, el viajero colombiano, se registra ejemplarmente la confluencia histórico-cultural que caracteriza a la ciudad como lugar conformado por capas de tensiones históricas:

Volvió a subir por la calle Velásquez hacia el Boulevard Pasteur y la plaza de Faro, donde había muy poca gente-limpiabotas y fotógrafos alrededor de los cañones portuguesesy las tiendas estaban cerradas con persianas de hierro. Unas cuantas golondrinas tempraneras revoloteaban por encima de los robles en el jardín del consulado francés. Dejando la decisión al azar, dobló a la calle de la Libertad, para bajar hacia el Zoco de Fuera. Pasado el hotel Minzah, se detuvo a mirar un escaparate atestado de puñales,

Revista Iberoamericana, Vol. LXXIX, Núm. 242, Enero-Marzo 2013, $149-162$
ISSN 2154-4794 (Electrónico) 
brazaletes y collares bereberes cubiertos de polvo que esperaban a sus compradores. Siguió bajando. Atravesó la plaza de hormigón del antiguo Zoco y entró en la Medina por la puerta del Campo. Siguió bajando hacia el Zoco Chico por la calle de los Plateros, donde había más gente; un aguador vertía el agua de un odre de cabra en escudillas de cinc. Las jóvenes, veladas o no, lanzaban miradas inquisitivas. Nada más distinto de la mirada de las caleñas, pensó. (51)

EnTánger no solamente permanecen las huellas de los dominios árabe y portugués, de la presencia española y francesa, sino que emerge la experiencia y la vivencia de un viajero (latino)americano que descubre en la mirada de las jóvenes mujeres el extrañamiento y distanciamiento de lo que antes le era familiar: las miradas de las mujeres de Tánger no son las de las mujeres de Cali. Este reconocimiento del colombiano conduce a mostrar la complejidad de las relaciones entre espacio e identidad. La identidad del colombiano, así como las de los demás personajes en la novela, se develará como una tensión con los espacios que transita, que se pone en marcha precisamente por medio de sus tránsitos por la ciudad, por espacios hechos de las ruinas y vestigios de las presencias e historias coloniales. En forma menos enfática se presenta esta cuestión en El tren a Travancore. En el episodio en el que el protagonista-escritor cuenta a su novia que ha sido llevado por su "rickshaw-wala" a un restaurante en el que "[l]os camareros indios estaban vestidos de cowboys, algunos con la estrella del sheriff en el chaleco americano, y todos con pistolas de cartón piedra en sus pistoleras” (21), la banalidad y lo irrisorio de esta situación en la ciudad india es contrastada seguidamente en el texto con la reseña de su arribo a la casa de la madre de su "taxista” para tomar el té después de la cena, una ceremonia que hace alusión oblicua a la presencia (pos)colonial inglesa en la India (ver Gutiérrez-Mouat). En ambas novelas, los recorridos espaciales de estos personajes activan un proceso oscilatorio de (des)identificación en varios niveles simultáneamente: con su lugar de origen, con el lugar al que han viajado y consigo mismos.

El siguiente episodio ilustra ejemplarmente dicho proceso. El viajero colombiano de La orilla africana ha perdido su pasaporte en Tánger y esto le significa, más que una frustración o un problema (que también podría serlo de orden identitario), la posibilidad de alargar su estadía indefinidamente. Consciente de haber perdido su pasaporte, el personaje imagina la fantasía que le podría finalmente desvincular de su lugar de origen:

Envuelto en una nube de humo de kif, sentado en posición de loto en su cama de la pensión, la espalda apoyada en la pared húmeda y fría, se inventaba un destino marroquí. No volvería a casa en mucho tiempo. Aprendería el árabe. Quizá hasta se haría musulmán. Compraría una esposa bereber. Había estado solo mucho tiempo. ¿Pero hacía cuántas semanas que estaba en Tánger? (84)

Su despedida se agudizará en dos episodios posteriores. En la segunda parte de la novela, el subcapítulo titulado "Collar" es una colección de cartas enviadas por la

Revista Iberoamericana, Vol. LXXIX, Núm. 242, Enero-Marzo 2013, $149-162$
ISSN 2154-4794 (Electrónico) 
novia del colombiano desde Cali. En las siete comunicaciones, que al igual que en las cartas indias de El tren a Travancore no consignan la fecha de su escritura, el lector es testigo de un gradual proceso de pérdida de la identidad del personaje, puesto que tanto su relación amorosa como su relación laboral y familiar se van diluyendo conforme se avanza en las lecturas de las cartas; ya en la última se lee: "Te anuncio que aquí ha habido cambios, algunos de ellos drásticos. [...] tu tío ha contratado a Víctor para que ocupe el puesto que has dejado [...]. Y yo (se me desgarra literalmente el corazón al escribirlo) me voy esta misma noche del apartamento, creo que para siempre” (135).

Así, mientras el colombiano recorre la ciudad junto a Julie Bachelier, la joven estudiante universitaria francesa que "estudiaba arqueología y se interesaba por el pasado romano y prerromano de la región” (92), el narrador explica: “Al llegar a la parte más alta del camino, él se detuvo y miró a Occidente, donde se abría el mar. Con cierta tristeza sintió que podía estar viendo aquel lugar por última vez" (124). Este sentimiento de pérdida y desarraigo va ser evocado por el narrador nuevamente en la tercera parte de la novela, cuando el personaje ya ha abandonado Tánger: "Subió por el paseo marítimo del General Macías hacia Medina Sidonia, atraído hacia allí por una nostalgia inexplicable, aquel sentimiento de pérdida que sólo había experimentado en Tánger” (143). Hacia el final de la novela, en un momento en el que este viajero anónimo, de quien el lector no conocerá el nombre sino hasta casi concluir la novela, no sabe hacia dónde enrumbar su viaje -si trasladarse a Almería con el transbordador o si volar a Málaga (143)- sus recorridos por la ciudad continuarán marcando el ritmo de su movilización, los cuales lo trasladan por un "sencillo laberinto", "a lo largo de las murallas", "por un callejón oscuro que se bifurcaba" hasta que toma una de esas bifurcaciones y se da cuenta de que "igual que tantos callejones de la Medina de Tánger, se iba angostando poco a poco, hasta convertirse en una especie de patiecito familiar" (144).

En este sentido, el paso por laberintos, murallas y callejones que se bifurcan conducen al personaje física y psíquicamente por estos espacios. No solamente su cuerpo experimenta y vive el movimiento, sino que también su subjetividad se halla en movimiento. Ni siquiera un encuentro fugaz y violento obstaculiza este estar en permanente movimiento, tampoco con quien es ahora el portador de su pasaporte perdido:

-¿Nos conocemos?-su voz sonó mal. Tragó una saliva ácida.

-Pero claro que te conozco, hombre.-Tenía un acento inesperado.

-¿En verdad? -respiró- Perdona, no te recuerdo. ¿Cómo te llamas?

-Ángel Tejedor-dijo el otro claramente.

-¿Cómo? -Algo extraño ocurrió en sus vísceras. El picor que sentía en todos los poros de su piel era la adrenalina generada por el susto. Las piernas comenzaron a temblarle ligera pero incontrolablemente. Ese, Ángel Tejedor, era su propio nombre-¿Es una broma?-atinó a decir. (144)

ISSN 0034-9631 (Impreso) 
La figura de Ángel Tejedor se desdobla como en un juego de espejos. La confusión y perplejidad del colombiano se transforman rápidamente en una lucha cuerpo contra cuerpo con el marroquí, donde ambos hombres forcejean hasta que se describe cómo uno de ellos queda tendido en el suelo mientras el otro, que se aleja del sitio, piensa que "era una encrucijada de colores y pulsaciones, y quizá no era suyo el hilo de sangre que escurría entre los adoquines disparejos hacia el fondo del callejón” (145). No solamente ha alcanzado físicamente la frontera que separa dos mundos, el mundo árabe islámico del occidental, sino que experimenta los límites de su identidad y la orilla de su subjetividad como un espacio de encrucijadas. En sintonía con este corrimiento de los límites y las fronteras, la novela cierra con la parte titulada "Fuga” y con una imagen que condensa precisamente esa condición de una vida en constante movimiento, de una existencia entre espacios y entre mundos metaforizada en el vuelo y en la búsqueda de la lechuza:

Se elevó hasta la cumbre del monte y vio, en la distancia, las luces vidriosas que iluminaban las colinas cubiertas por un manto de casa blancas que se perdían entre los pliegues del campo sediento y agrietado. Bajó para volar sobre las copas de los árboles hacia una casona abandonada en medio de un bosque tupido. Entró por una ventana y fue recibida por los gritos de los pájaros que ya anidaban allí. Recorrió la casona volando de cuarto en cuarto por los pasillos hasta que encontró una hendidura conveniente en la pared áspera y oscura de un desván, donde faltaban algunas tejas y las tablas del piso estaban rotas o completamente podridas. (157)

La profunda metáfora de la búsqueda de un lugar donde resguardarse lleva al lector a seguir el vuelo de la lechuza mientras recorre la casona, sus antiguos cuartos y pasillos ya abandonados por las vidas humanas que alguna vez la habitaron. En este lugar pareciera que finalmente ha encontrado dónde asentarse, allí "donde faltaban algunas tejas y las tablas del piso estaban rotas o completamente podridas” (157), allí donde la literatura deja de tener una residencia fija.

\section{PoR UNA POÉTICA DEL MOVIMIENTO}

Tal y como lo muestran las novelas, ambos autores recurren a un elevado número de figuras relacionadas literaria, física, emocional y perceptivamente con el movimiento. Así, por ejemplo, encontramos en el caso de Castellanos Moya figuras como la analepsis, la diáspora, la dispersión, los (des)encuentros, la revolución, la espera, y, en el caso de Rey Rosa surgen otras como el viaje, las cartas, las comparaciones, los laberintos y el vuelo. Estas figuras, según mi propuesta de una poética del movimiento aquí esbozada, además de cumplir con una función narrativa dentro de la composición de la diégesis, contienen una clara dimensión poética. Con esto me refiero a que ellas componen diversas figuras no sólo del movimiento, sino también sobre el movimiento en y de la literatura.

\footnotetext{
Revista Iberoamericana, Vol. LXXIX, Núm. 242,
ISSN 0034-9631 (Impreso)
} 
En los casos aquí analizados dichas figuras tienen una relevancia tanto hermenéutica como política, epistemológica y poética para la comprensión de las relaciones entre el movimiento, la época histórica de Centroamérica en la que se enmarcan las novelas, el espacio y la subjetividad. Estas otras figuras sobre el movimiento se arman en las formas de la oscilación, la fuga, la circularidad, el distanciamiento y la bifurcación.

Con respecto a la época histórica, los movimientos presentados por las novelas atraviesan las cuestiones del exilio, la fragmentación, el desencanto político, la transición y la fase actual de globalización acelerada como condiciones de una incertidumbre local y transnacional entre el pasado y el futuro de los proyectos políticos, haciendo surgir las cuestiones y preguntas por la sociabilidad y la convivencia en la Centroamérica de posguerra. En cuanto al espacio, los movimientos descomponen los procesos de reconocimiento e identificación basados en la seguridad y estabilidad territoriales que los proyectos nacionales habían generado, a través, por ejemplo, de la centralización y fijación de las identidades en representaciones excluyentes de sectores importantes de la población, en la supuesta impermeabilidad y estabilidad de las fronteras (nacionales) y en la imagen de la pertenencia. La pregunta por la identidad es desplazada y relativizada por las incesantes búsquedas que los personajes escenifican. A la vez, los viajes se dan tanto cruzando las fronteras entre lo urbano y lo rural como entre los recorridos a pie, en autobús, en tren o en avión que bordean murallas y callejones, que cruzan fronteras nacionales y culturales, y éstos se combinan con los viajes transnacionales y hemisféricos (Colombia, El Salvador, Guatemala y México) y transatlánticos (América, África y la India) para con ello producir geografías y cartografías dinámicas basadas en los movimientos, en los desplazamientos y en las experiencias y vivencias de lo otro, lo diferente.

Con esta estrategia poética, que es a la vez epistemológica y hermenéutica, estas tres novelas producen una serie de preguntas pendientes a nuestros modelos de entendimiento de las distancias (geográficas, sociales y culturales), de las identidades, de las identificaciones y de los reconocimientos. Además de servir a una revisión y relectura de una época histórica y de un espacio específico transnacional y transístmico, las figuras del movimiento tienen efectos claramente visibles en los personajes, ejemplarmente en las formas de producción, reconfiguración, búsqueda y expresión de sus subjetividades. Tanto los viajes como las demás figuras sobre y del movimiento aquí mencionadas plantean la pregunta por el yo y por el otro como una experiencia (Erfahrung) y una vivencia (Erlebnis) que no se reducen a la historia personal de los protagonistas, sino que invocan las consecuencias que ellas tienen para pensar formas posibles del nosotros, de la sociabilidad y de la convivencia en la diferencia.

He querido proponer aquí solamente una forma de organización y articulación entre varias posibles colocando como lógica fundamental para la comprensión del presente la pertinencia de los recorridos, los movimientos, así como de las historias entrelazadas

\footnotetext{
Revista Iberoamericana, Vol. LXXIX, Núm. 242, Enero-Marzo 2013, $149-162$
ISSN 2154-4794 (Electrónico)
} 
y conectadas entre sí que la literatura hace presentes y tiene la capacidad de mostrar. En este decantamiento Centroamérica se convierte en una construcción en la que la literatura juega un papel fundamental, no solamente demostrando que ella es una ficción y una construcción literarias, sino también conduciendo a pensarla, a aprehenderla y a reprensarla como espacio dinámico e interactivo de los textos literarios y sus movimientos.

\section{BiBLIOGRAFÍA}

Augé, Marc. Los no lugares. Espacios del anonimato. Una antropología de la sobremodernidad. Madrid: Gedisa, 2008.

Bajtin, Mijail. Problemas literarios y estéticos. Tatiana Bubnova, trad. México: Fondo de Cultura Económica, 1986.

Beverley, John y Marc Zimmerman. Literature and Politics in the Central American Revolutions. Austin: U of Texas P, 1990.

Castellanos Moya, Horacio. La diáspora. San Salvador: Dirección de Publicaciones e Impresos, 2002.

Cazali, Rosina, ed. Pasos a desnivel. Mapa urbano de la cultura contemporánea en Guatemala. Guatemala: Hivos/La Curandería, 2003.

Cuevas Molina, Rafael. Traspatio florecido. Tendencias de la dinámica de la cultura en Centroamérica (1979-1990). Heredia: Universidad Nacional, 1995.

Ette, Ottmar. Literatura en movimiento. Espacioy dinámica de una escritura transgresora de fronteras entre Europa y América. Rosa María S. de Maihold, trad. Madrid: Consejo Superior de Investigaciones Científicas, 2008.

Geyer, Michael y Charles Bright. "World History in a Global Age”. American Historical Review 100/4 (1995): 1034-60.

Gutiérrez-Mouat, Ricardo. “El tren a Travancore de Rodrigo Rey Rosa: el relato de viajes fraudulento”. Ciberletras 20 (2008). <http://www.lehman.cuny.edu/ciberletras/v20/ gutierrezmouat.html>. 20 agosto 2009.

Leyva, Héctor M. "Las fisuras del testimonio". Istmo. Revista virtual de estudios literarios y culturales centroamericanos 16 (2008). <http://collaborations.denison. edu/istmo/n16/articulos/leyva2.html>. 1 junio 2008.

“Narrativa de los procesos revolucionarios centroamericanos 1960-1990.” Tesis doctoral. Madrid: Universidad Complutense de Madrid, 1995.

Liano, Dante. Visión crítica de la literatura guatemalteca. Guatemala: Editorial Universitaria Universidad de San Carlos de Guatemala, 1997.

López, Silvia L. "National Culture, Globalization and the Case of Post-War El Salvador". Comparative Literature Studies 41/1 (2004): 80-100.

Mackenbach, Werner. Die unbewohnte Utopie. Dernicaraguanische Roman der achtziger und neunziger Jahre. Frankfurt am Main: Vervuert, 2004.

ISSN 0034-9631 (Impreso) 
Mackenbach, Werner, ed. Intersecciones y transgresiones: Propuestas para una historiografía literaria en Centroamérica. Hacia una historia de las literaturas centroamericanas. Vol. I. Guatemala: F\&G, 2008.

McClennen, Sophia A. The Dialectics of Exile. Nation, Time, Language, and Space in Hispanic Literatures. West Lafayette: Purdue UP, 2004.

Ortiz Wallner, Alexandra y Werner Mackenbach. "Publicaciones sobre literatura y procesos culturales centroamericanos contemporáneos. Una selección bibliográfica.” Istmo. Revista virtual de estudios literarios y culturales centroamericanos 15(2007). $<$ http://collaborations.denison.edu/istmo/n15/proyectos/biblio.html>. 1 junio 2008.

Pizarro, Ana. El archipiélago de fronteras externas: culturas del Caribe hoy. Santiago de Chile: Universitaria, 2002.

Ramírez, Sergio. "Balcanes y volcanes (Aproximaciones al proceso cultural contemporáneo de Centroamérica)”. Centroamérica: Hoy. Edelberto Torres Rivas, y otros, eds. $2^{\mathrm{a}}$ ed. México: Siglo XXI, 1975. 279-366.

Rey Rosa, Rodrigo. La orilla africana. Barcelona: Seix Barral, 1999. El tren a Travancore (Cartas indias). Barcelona: Mondadori, 2002.

Rodríguez, Ana Patricia. Dividing the Isthmus: Central American Transnational Histories, Literatures, and Cultures. Austin: U of Texas P, 2009.

Werner, Michael y Bénédicte Zimmermann. “Penser l'histoire croisée: entre empirie et réflexivité”. Annales. Histoire, Sciences Sociales 58/1 (2003): 7-36.

Revista Iberoamericana, Vol. LXXIX, Núm. 242,
ISSN 0034-9631 (Impreso) 